\title{
EXAMINING SPILLOVER OF SUSTAINABLE BEHAVIOUR: AN INTERVENTION STUDY FROM THE PERSPECTIVE OF MALTESE PUBLIC OFFICERS.
}

\author{
Clinton Cassar \\ University of Malta, Msida, Malta
}

\begin{abstract}
A B S T R A C T
It has long been acknowledged that the various burgeoning problems inflicting the world are deeply rooted in human behaviour. Governance often entails policy formulation and strategies that initiate behavioural change to alleviate such problems and foster sustainability. However, this often appears as a strenuous endeavour, especially at the macro level. For this reason, implementing the behavioural spillover mechanism is deemed befitting. Few studies have directed their attention towards the relationship of individuals' sustainable behaviour across different settings, and such a perspective could indicate the way forward required within various future policy frameworks. Hence, the following intervention study attempts to examine behavioural spillover, which entails the transfer of attitudes from one domain to another, in this case, from a work-home perspective. This chapter builds upon such notion through a case study from the Maltese islands, the smallest EU member state, by providing insights from public officers. Such sampling population was selected as these individuals work closely within governmental structures and should act as agents of change in this regard. The methodological framework employs a positivist paradigm, based on a quasi-experimental design through an identical pretest and posttest Likert-scale questionnaire distributed to 14 public officers who undertook an educational module about sustainability at the University of Malta. These tests aimed to examine whether spillover of sustainable behaviour occurs within a spatio-temporal context - across the two different domains and during the entire intervention adopted. Quantitative findings are utilized to address two core research questions, from which various trends have been identified. Results show that positive spillover occurs for those behaviours which involve the least time, cost, and effort. It transpires that respondents are not willing to adopt drastic lifestyle changes. Such findings lay the foundation for the recommendations delineated in the current study, which might be helpful to other practitioners in public policy, management, and sustainable development.
\end{abstract}

\author{
ARTICLE INFO \\ Keywords: Behavioural Spillover; \\ Pro-Environmental Behaviour; \\ Sustainability; public officers; \\ policy; governance
}

\section{*Corresponding author: \\ clinton.cassar@um.edu.mt}

Article history:

Received :16.10.2021

Revised : 28.11.2021

Accepted :07.12.2021

DOI :

https://doi.org/10.51410/jcgirm.8.2.2

\section{INTRODUCTION}

In the wake of the ever-increasing issues inflicting the world, public administrations should adopt innovative measures to address and campaign for behavioural changes that would translate into fewer environmental impacts and eventually verge towards sustainability. Whitmarsh (2009) warns that changing behaviours, especially at the macro level, appear to be quite strenuous, and a myriad of resources are needed to accomplish such a task. Thøgersen and 
Crompton (2009, p.142) assert that this necessitates 'far-reaching changes in individual behaviour, fundamental changes in business practice, and the implementation of ambitious new policies and regulations to drive interventions'. Being an underexplored area for many years, the notion of behavioural spillover seems to have gained ground recently within academic and policy contexts, as indicated by Austin et al. (2011), Truelove et al. (2014), and Nilsson et al. (2016) as cited in Galizzi and Whitmarsh (2019).

Besides shedding light on personal traits and pursuits through a psychological outlook, embodying the aforementioned in policy and governance is necessary. This can trigger a multiplier effect that might lead to a societal transformation. Capstick, Lorenzoni, Corner and Whitmarsh (2015) outline that such measures appear promising since they holistically address the shift towards sustainability rather than the small-scale and personal interventions carried out many a time in isolation.

Even though behavioural spillover often lends itself to the effects of the work domain on personal relationships, this chapter seeks to expose it across different domains, tackling it from a sustainable point of view. In this respect, the following section presents the objectives of this research in further detail.

\subsection{Research Scope}

The permeability between work-family relations has been the central motif of many studies such as Byron (2005); Eby et al. (2005), as cited in Sikora et al., (2007). However, as outlined in the introduction, the present research tries to fill the void concerning implementing sustainable behaviour across different settings as promulgated by Thøgersen (2012) and Tudor, Barr and Gilg (2007). Taking this into account, research is marshalled from the perspective of the Maltese islands, being the smallest EU member state and located in the middle of the Mediterranean, with a population marking half a million people (The Malta Independent, 2020) over an area of 316 square kilometres (NSO, 2014).

This study aims to examine the foregoing notion through a case study approach by expanding on research from previous studies. In addition, it shall scrutinize behavioural traits from the perspective of public officers who undertook an educational module at the University of Malta. 
Thus, attention shall be directed towards the spatio-temporal spillover of sustainable behaviour between work and home by answering two core research questions:

(i) Are there any similar or different behavioural trends between work and home?

(ii) To what extent does the intervention utilized affect behaviour?

Answering these research questions will provide significant insights that contribute to existing knowledge in the field of human behaviour, sustainability and public administration. However, the results might also be applied to other spheres and may lay the foundation to further studies.

This chapter is divided into several sections. The first part examines the theoretical underpinnings of the research by exploring behavioural spillover and relevant theories. This is followed by the methodological framework employed, which is substantiated in the next section, where the findings are rolled out. Finally, the concluding part is reserved for answering the research questions and some relevant recommendations from the research outcomes.

\section{THEORETICAL FOUNDATIONS}

\subsection{Behavioural Spillover - A definition}

Spillover refers to the intra-individual transfer of knowledge, attitudes, or behaviour from a given domain to another (Geller, 2001; Poroli and Huang, 2018; Rodriguez-Muñoz et al., 2013; Littleford et al., 2014; Poortinga et al., 2013 as cited in Galizzi and Whitmarsh, 2019).

It has often been argued that pro-environmental behaviour (PEB) might initiate other positive behaviour in diverse areas (Gray, 1985; McKenzie-Mohr et al.,1995; Pickett et al.,1993 as cited in Thøgersen, 2012). Crompton (2008) also adds that individuals often perform inconsequential sustainable behaviour for their merit or refuse other behaviours that encourage substantial changes to their lifestyle. This is mainly attributed to factors such as inertia, denial and dislike of sacrifice (Oskamp, 2000) or values that do not align or directly affect one's 'interest, needs and existing attitudes’ (Rogers, 2003, p.171).

Spillover can take place in three different manners: (i) The behavioural spillover occurs when one type of behaviour will affect another type of behaviour; (ii) The temporal spillover takes 
place within a specific timeframe; (iii) Contextual spillover happens within established contexts or settings.

In this research, all spillover types mentioned above are fused and embodied in the work-home spillover. It focuses on the transfer of positive and negative behavioural traits between work and home. Their effects on one another are essential to 'generate similarities between the two domains' (Edwards and Rothbard, 2000, p.180). The authors mentioned above also add that the work-family domains, also referred to as work-family facilitation or work-family enrichment, can promote similar pro-environmental behaviours between them. However, Rashid and Wahid (2012) point out that behaviours might interfere positively or negatively.

After introducing the concept of behavioural spillover, the next section discusses in more detail the different types of positive and negative spillover, together with their archetypes promoting, permitting, and purging spillovers.

\subsection{Types of Positive Spillover}

Positive spillover is when an initial PEB leads to a subsequent sustainable behaviour (Thøgersen and Crompton, 2009). It is multi-dimensional and often occurs through four bivariate dimensions - affect, values, skills, and behaviours (Hanson, Hammer, and Colton, 2006). A type of positive spillover is known as promoting spillover, which involves a type of impetus to further increase the desired behaviour in the future. Within 'promoting spillover', Dolan and Galizzi (2015) mention the following archetypes:

(i) Cognitive dissonance refers to the self-awareness of unsynchronized actions and behaviour and their eventual conflict resolution by aligning them with one's worldviews.

(ii) Similarly, in promoting consistency, is the notion of 'Foot-in-the-door' which relies on what Thøgersen and Crompton (2009) refer to as 'salesman tricks'. Futerra adds that it means to

get someone to do something small and then introduce another more significant action once the small one is completed. The move upwards will not just happen on its own: communications are needed to link each rung of the ladder (2006, p.10). 
(iii) The Intention-behaviour concept mainly postulates that the degree of intention can influence subsequent behaviour.

(iv) Moreover, a Question/behaviour survey can serve as a reminder of certain behaviours that have been neglected.

(v) Rationality crossover uses economic rationality in market-like behavioural settings to an eventual behaviour devoid of financial incentives (Cherry and Shogren, 2007). This same concept has also been applied to field-lab spillovers.

\subsection{Types of negative spillovers}

Negative spillover happens when a successful PEB is linked with a reduction in another type of behaviour (Thøgersen and Crompton, 2009). Negative spillovers are coined with permitting spillovers, which signifies a subsequent disengagement from the initial motive. These include, as highlighted by Dolan and Galizzi (2015):

(i) Ego depletion occurs when high self-control in the first behaviour diminishes because of the subsequent behaviour.

(ii) Moral licensing happens when moral entitlement to the subsequent behaviour has been attributed to the positive outlook towards the initial behaviour.

(iii) The reverse foot-in-the-door effect occurs when an affirmative outlook towards the initial behaviour will lead to a negative response to a subsequent one (Guadagno, Asher, Demaine and Cialdini, 2001).

(iv) The Resting on laurels effect occurs when progress towards a particular behaviour is seen as a sub-goal, and as a result, less effort is placed on the ultimate goal (Mazar, Amir and Ariely, 2008).

(v) The single-action bias implies that no further action is needed for an initial purpose when in reality, further effort would be helpful (Weber,1997).

(vi) Coasting, where effort towards a particular motive diminishes since it is assumed that a previous action is sufficient (Carver, 2003).

Purging spillovers imply a conscious or unconscious desire stemming from the second behaviour to remediate some of the damage caused by the initial behaviour. Dolan and Galizzi (2015) point out that such spillovers include: 
(i) Moral cleansing is the opposite of moral licensing since, after a negative outcome on one's morality, an individual tries to restore his or her dignity. People tend to act morally when moral cleansing occurs, and their self-image is threatened.

(ii) Conscience accounting is when individuals are more likely to donate due to illicit earnings than individuals who have earned income without deception.

(iii) The transgression-compliance effect and the negative state relief focus on restoring personal values, which have been subject to negative influences, by acting more altruistically.

This section has confirmed that various requirements are needed for behavioural spillover to take place. According to Nash et al. (2017), the implementation of spillover is determined by two psychological approaches, which are: (i) self-perception, identity or consistency, and (ii) self-efficacy, knowledge, or self-motivation. The former emphasizes an individual's perception of oneself and the will to act consistently with that self-image. On the other hand, the latter involves the confidence attained in one behaviour which motivates the shift in another behaviour.

Furthermore, the climate within such different settings also determines the success of spillover. Rashid and Wahid (2012) postulate that any organizational structure should clearly define its goals and provide the necessary training to upskill employees. Family cohesion and support are essential within the other domain, where the focus is placed on the extent to which family members share common values and enjoy each other's company. Even though the factors above need to be considered in behavioural research, contextualizing them within regulatory frameworks should be deemed necessary for its successful implementation, as discussed in the next section.

\subsection{Implications of Behavioural Spillover on policy and governance}

Hale (2008, p.262) emphasizes that 'political mobilization is the most critical' regarding sustainable behaviour. He even seems to agree with Rogers's vision (2003, p. 29), who states that achieving accelerated results from mechanisms that promote behavioural change need to 'stem from authority decisions'. Envisaging 'behavioural silos', as postulated by Thøgersen (1999), where only one particular behaviour is observed, should be avoided since no 
behavioural traits manifest themselves in a vacuum. Hence, as Hale warns, such situations call for a collaborative effort in order to be fruitful:

The impasse between government, business and individuals must, somehow, be broken... If we are to do so, we must understand the kind of public intervention that will make a difference... It is governments that determine the carbon intensity of the energy we use in our homes, the price and availability of different modes of transport and the relative price and carbon intensity of the goods and services that we buy... So the critical issue is not simply our behaviour, but the impact of our activism, behaviour and attitudes on political action (2008, p.12).

In response to this, The UK government's Department for Environment, Food and Rural Affairs (Defra) promotes the need 'to promote a range of behaviours as entry points in helping different groups to make their lifestyles more sustainable - including catalytic behaviours if identified through research' (Defra, 2008, p.22). Most sustainable policies aim to formulate a holistic vision, recently including behavioural studies. That is why behavioural spillover appears advantageous for policymakers since it can change a wide array of behaviours 'in a costeffective manner with little regulation which might be politically unpopular' (Galizzi and Whitmarsh, 2019, p.1). Effective policies should create snapshots of 'all ripples of behaviour when a pebble of intervention is thrown in the pond' (Dolan and Galizzi, 2015, p.2).

Indeed, policy should be seen more as an intervention in the form of educational campaigns and tax incentives that serve as catalysts towards sustainable behaviour. This creates a chain reaction where the success of a $\mathrm{PEB}$, through positive spillover, might warrant investment in additional policies. On the other hand, negative spillover indicates the requirement of more adequacy or redesign in policy formulation. Gillingham et al., (2013) and Jacobsen, Kotchen and Vandenbergh (2012) tend to disagree with the latter since the incidence of negative spillover does not translate into ineffective policy, but rather act as an indication of what underlying factors contributed to such results. Most importantly, the notion of spillover within such contexts should not be solely seen as a means to adhere to national or international legislation but more as a vehicle for stakeholders to be proactive. That is why the government, the general public and civil society should collaborate to search for solutions that initiate change.

Truelove, et al., (2014, p.128) assert that 'spillover research can better inform energy and environmental policy if it accounts for insights from relevant social science disciplines and examines spillover effects in realistic settings'. Thus, a better understanding of the 
psychological underpinnings can improve policy design by foreseeing when positive or negative spillover might occur, which happens to be one of the main objectives of this study. As delineated in the following section, human behaviour within two realistic but distinctive settings is analyzed to provide valid contributions towards policy and governance.

\section{METHODOLOGICAL FRAMEWORK}

Since the central theme of this study is rooted in behavioural research, a positivist paradigm grounded in objectivism epistemology was adopted, focusing on the methods of natural sciences to discover the study of social science (Crotty,1998, p.8). It tries to interpret findings linked to facts or measurable entities (Fadhel, 2002). Moreover, a quasi-experimental design, also referred to as 'field experiment' or 'in-situ experiment' Levy and Ellis (2011), was deemed befitting. The prefix 'quasi' signifies resembling experimental research, and it suggests that it mimics actual experiments, hence why quasi-experiments are considered a subtype of nonexperiments. The quasi-experimental design relies on an empirical interventional study that highlights the influence of the independent variable on the dependent variable (Loewen and Plonsky, 2015) through varying degrees of change or variation. The former in this research refers to public officers' behaviour, whereas the latter refers to the intervention, which is the educational module.

A tool of quasi-experimental design and which is utilized in this research is a one-group pretestposttest design. The dependent variable is measured before treatment commences, known as the control condition and once again after its completion, referred to as the treatment condition (Price et al., 2017). Stratton (2019) states that the pretest and posttest design involves the 'assessment of specific representatives of a population of interest, but not of the population as a whole' based on their 'attitudes or perceptions relative to an event, or to assess comfort in applying the information presented in a training session or with the introduction of a new concept'. Allen (2017) accentuates that an essential prerequisite for the pretest and posttest design is that the same type of treatment and opportunity is provided to a single group of participants.

Concerning this study, the population of interest involves 14 public officers who attended an educational module about sustainability at the University of Malta. The stages of pretestposttest design include these three steps: 
(i) Administering the pretest: each student, based on confidentiality and anonymity, carried out a Likert-type questionnaire at the beginning of the educational module in October 2020.

(ii) Providing the treatment: Up till January 2021, the 14 respondents all completed the education module.

(iii) Completing the posttest: Upon the module's completion, a posttest Likert-type questionnaire, identical to the pretest, was carried out.

Such tools garnered quantitative data, which is essential to answer the research questions outlined in the research scope. This is carried out to evaluate how the information presented in the educational module has affected sustainable behaviours both at work and home.

While the pretest and posttest prove advantageous in offering directionality, only associations can be obtained since it is not a true experimental design (Stratton, 2019). More often than not, the effectiveness of the intervention rests on the improvement in results. However, the limitations of this methodological tool relate to internal validity. As explained below, the following threats were controlled as much as possible:

(i) History focuses on external factors outside the research scope that influence the changes between the two tests. For example, even though all participants attended the same educational module, external factors influencing one's life might contribute to a behavioural change, which, alas, is an integral part of the study.

(ii) The selection of participants guaranteed that all students were invited to participate and given the same treatment throughout.

(iii) Experimental mortality emphasizes the right of respondents to drop out at any instance from this study. However, all students agreed to carry out both tests.

(iv) Instrumentation implies that the same method and questions were used in both tests, as carried out in this study.

(v) Instrument reactivity refers to the influence of the pretest on the posttest. Before each test, respondents were reminded to answer as truthfully as possible and that there was no correct or incorrect answer. 
The understanding of this phenomena, based on behavioural and attitudinal change across time and domains, is in line with Baldwin's line of thought (2018) who rightly states that it focuses on 'how much of a change actually occurred or how much growth occurred between the pretest and the posttest'. Consequently, as the methodological framework has been delineated, the following section presents the findings of this study.

\section{RESULTS AND FINDINGS}

This section displays some stacked bar graphs revealing pertinent quantitative data obtained from Likert-scale questionnaires at the start and end of the intervention utilized. The main objective of the questionnaire is to delineate to what extent the respondents perform the selected behaviour to determine any common spatio-temporal trends.

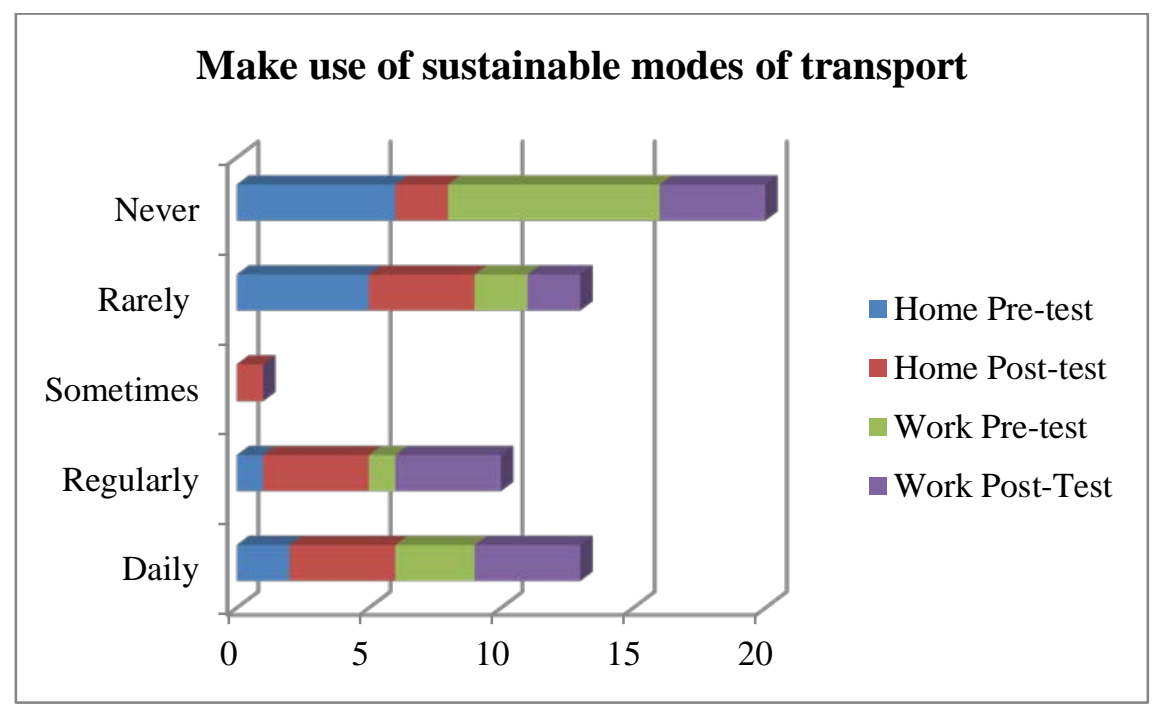

Figure 1: The use of sustainable means of transport

As seen in Figure 1, the pretest of attitudes at work and home share similar results since the never category scored the highest result, whereas the sometimes option scored the least. Furthermore, the daily and regularly categories shared similar behavioural results for the posttest in both domains. Interesting to note that the sometimes category scored no results, except in the posttest for behaviour at home. 


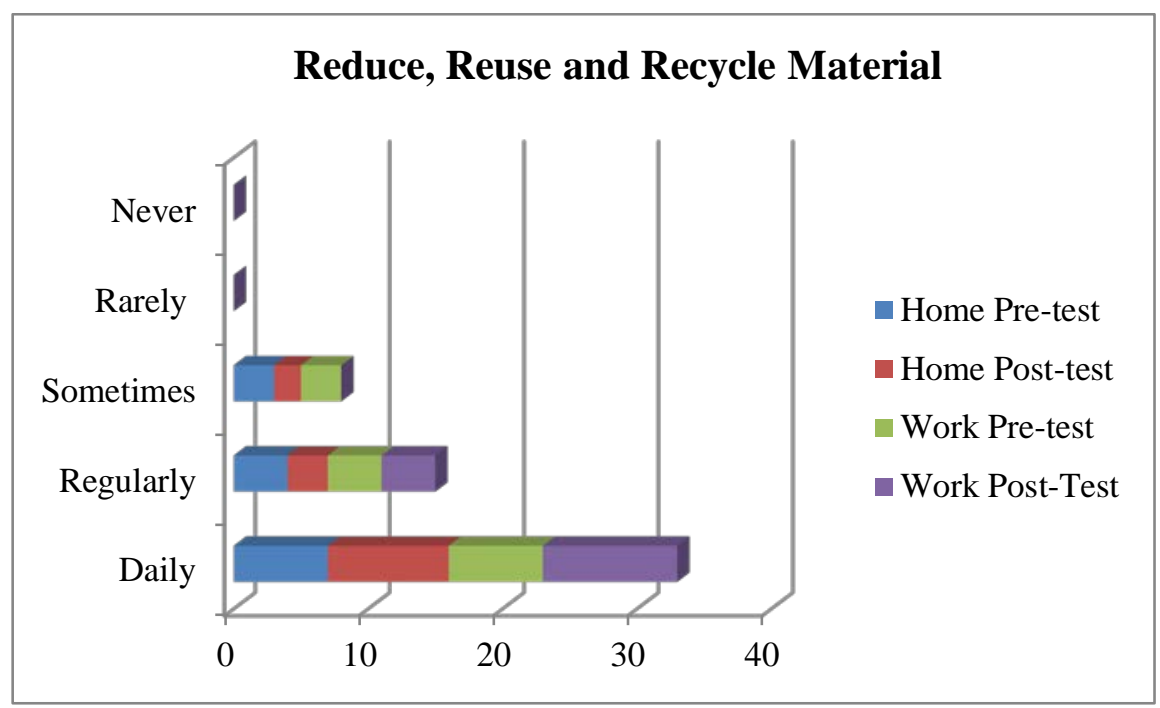

Figure 2: The practice of reducing, reusing and recycling

Figure 2 displays that the never and rarely categories scored no data, whereas the daily category garnered the highest amount of data in both pretest and posttest for both domains. It seems that respondents reduce, reuse and recycle consistently both at home and at work.

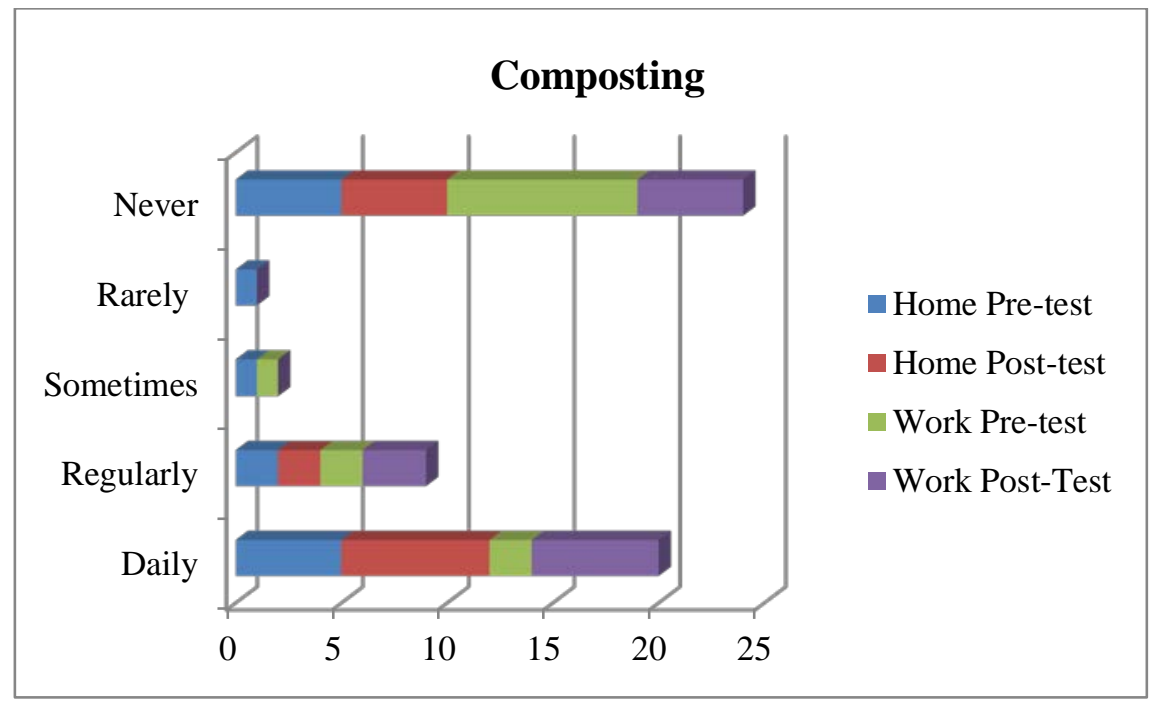

Figure 3: The practice of composting

As displayed in Figure 3, the never category scored the highest data altogether, with the work pretest scoring the highest in this category. On the other hand, the rarely category obtained no scores, except for one respondent in the home pretest. However, the daily category also shows that the data increased for both the home and work posttest when compared to the pretest. 


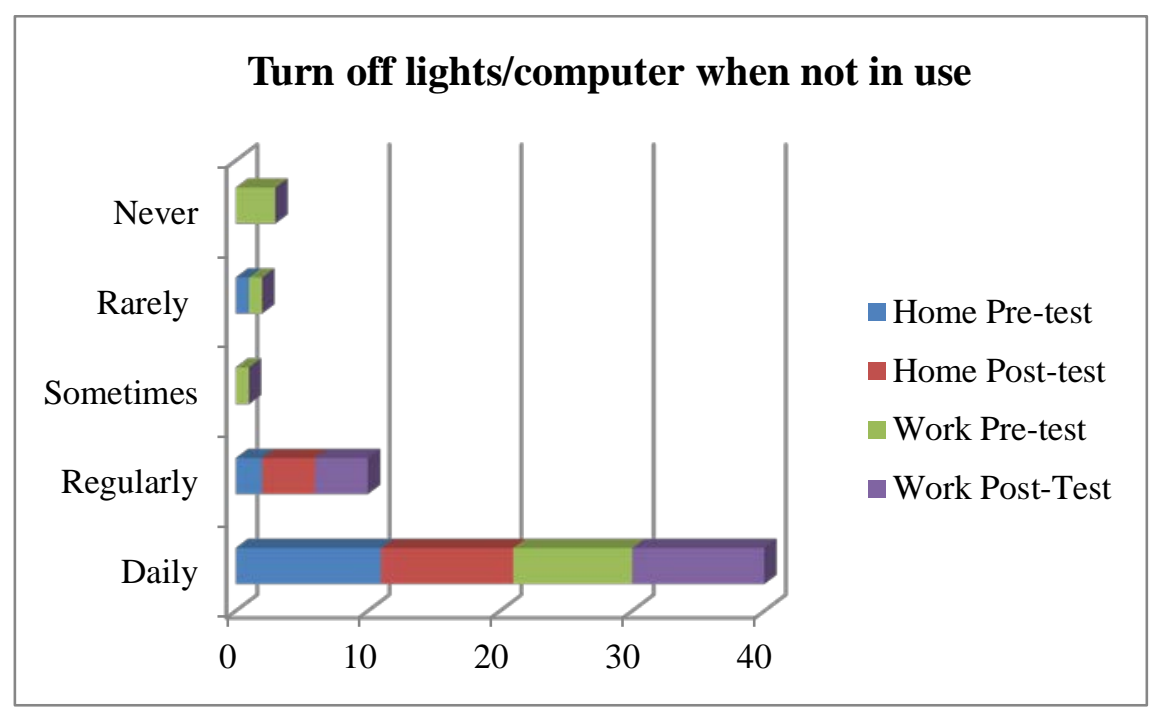

Figure 4:The practice of controlled electrical consumption

Figure 4 demonstrates that the daily category was strongest for both domains both in the pretest and posttest. The negative strands of the Likert scale scored low or no data.

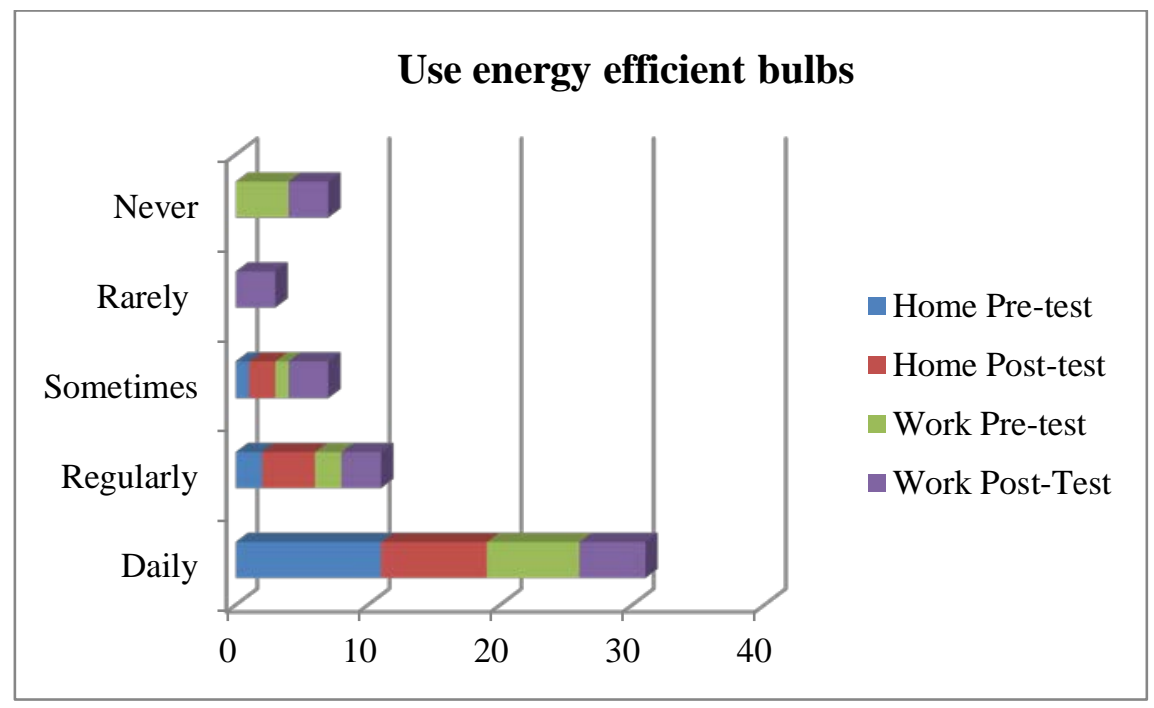

Figure 5: The use of energy-efficient bulbs

Interestingly, Figure 5 highlights that the rarely category scored data only in the work posttest. The work posttest scored the same results in nearly all categories, except the daily category, which scored the highest. However, unlike the sometimes and regularly category, the posttests for both domains decreased in the daily category compared to the pretest. The never and rarely category garnered data only from the work pretest and posttest. 


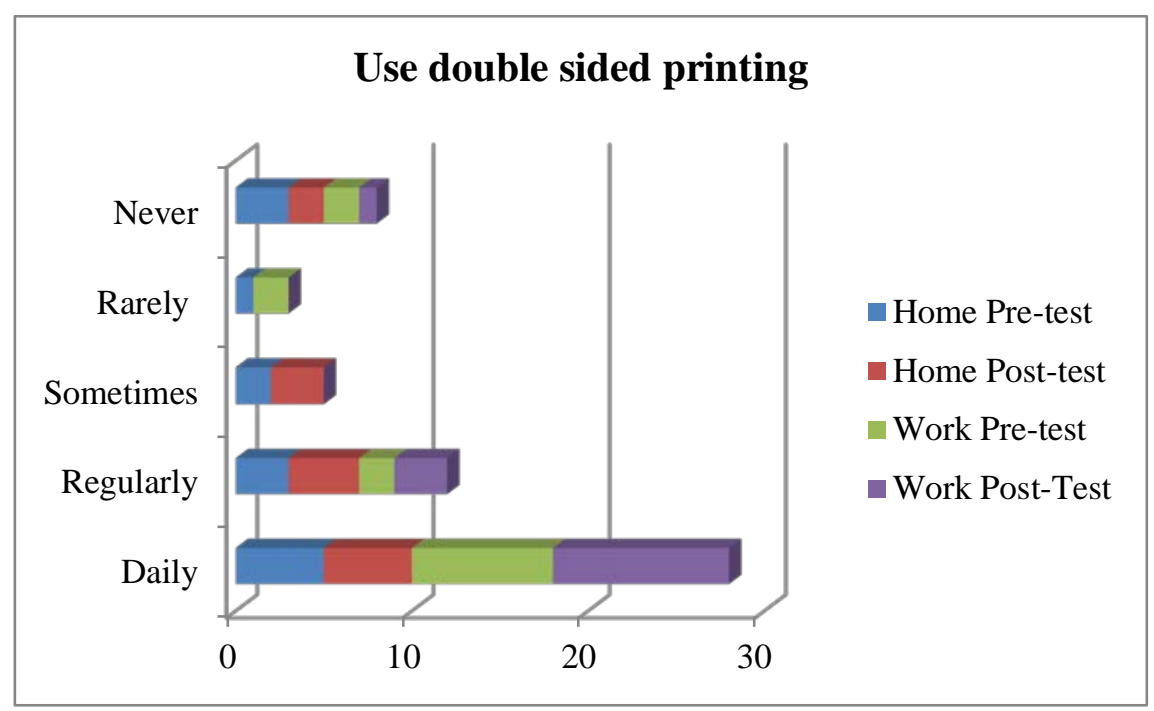

Figure 6: The practice of double-sided printing

While observing the results in Figure 6, one can notice that the daily category scored the same results for the home pretest and posttest. On the other hand, double-sided printing increased at work between the pretest and posttest. Furthermore, the rarely category scored the least data altogether while the sometimes category scored data only in the home domain.

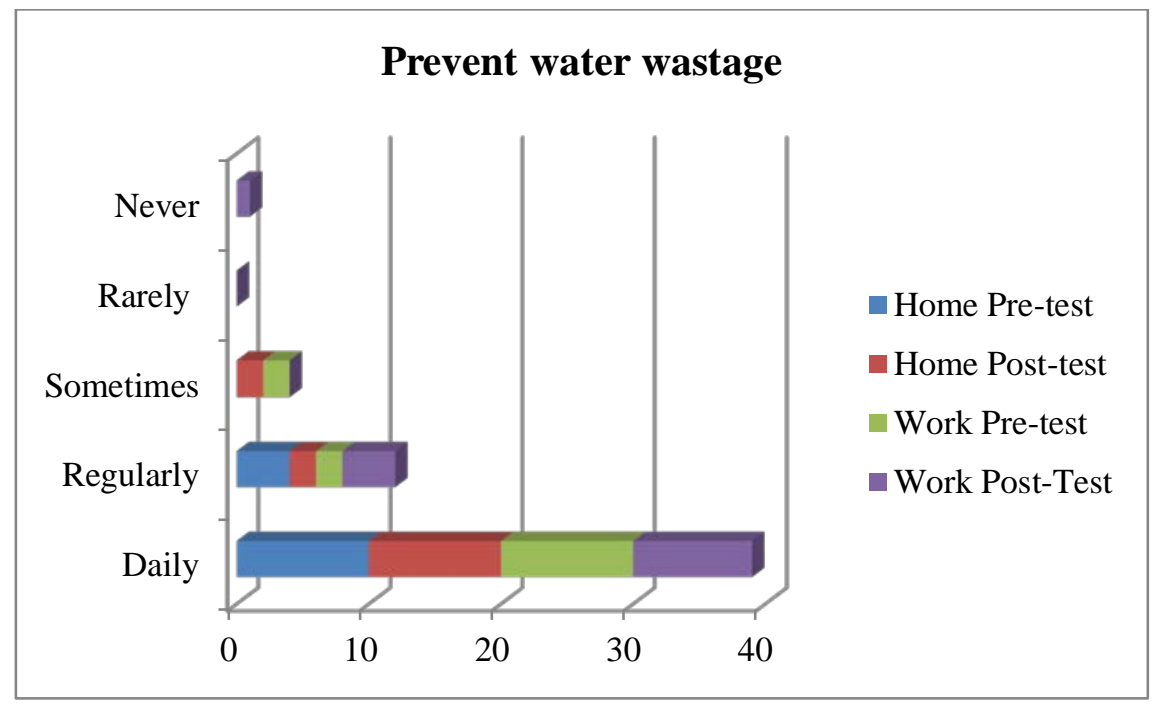

Figure 7: The practice of water wastage prevention

Figure 7 exhibits nearly no data for the negative strands of the Likert Scale since the daily category scored the majority of data. 


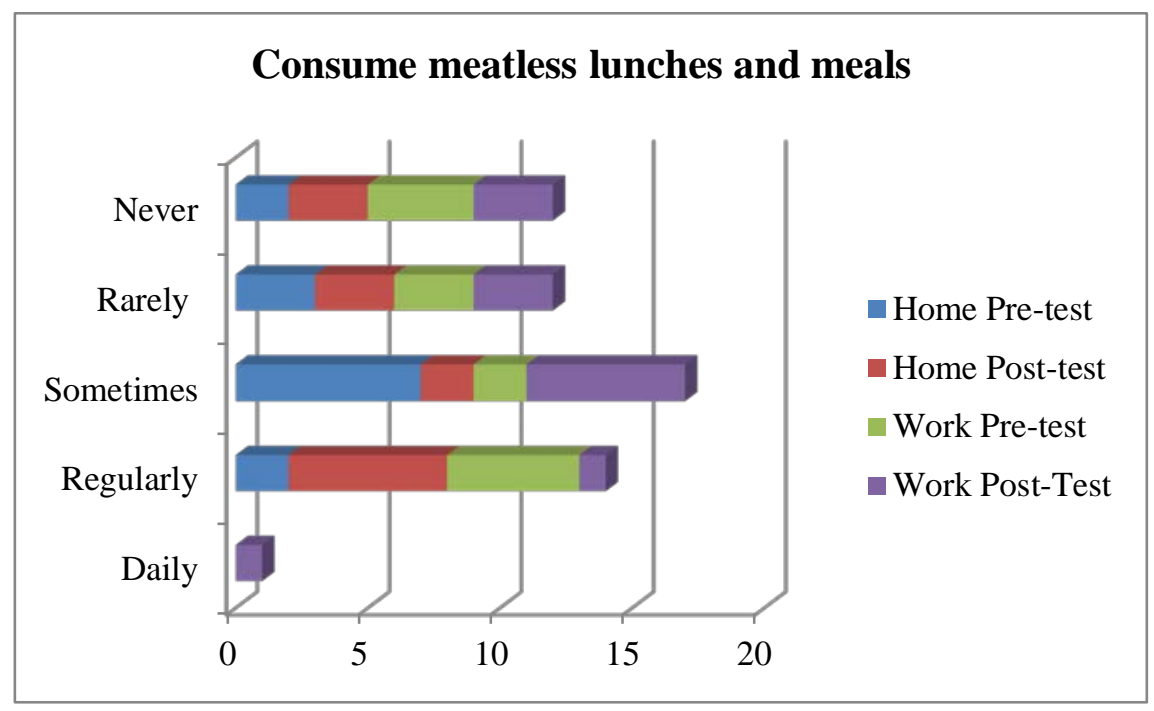

Figure 8:The consumption of meatless meals

Figure 8 reveals that the daily category scored the least amount of data, whereas the sometimes category scored the highest. Overall, the negative strands of the Likert Scale garnered the most results, implying that respondents are not willing to consume meatless lunches and meals both at work and home.

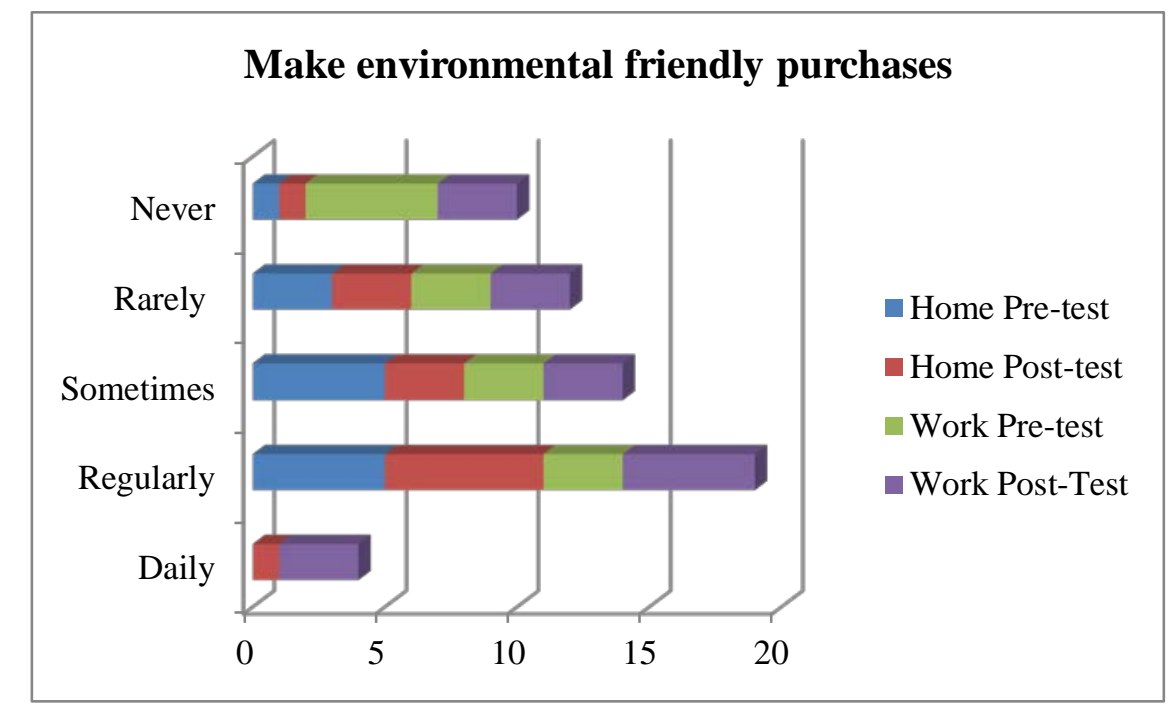

Figure 9: The practice of environmental friendly purchases

Figure 9 indicates that the daily category scored the least amount of data, both from the posttest at home and work. The regularly category scored the highest. However, the negative strands achieved a considerable amount of data as well. 
Once the findings have been rolled out, the following section presents a discussion by answering the core research questions delineated in the research scope.

\section{DISCUSSION}

\subsection{Answering Research Question 1}

Research Question 1: Are there any similar or different behavioural trends between work and home?

The findings illustrate minimal differences between behaviours at home and work, echoing Edwards and Rothbard's (2000) words as mentioned in the theoretical component of this paper. Overall, respondents demonstrate consistency in behavioural traits irrespective of settings, fostering behavioural spillover. Interesting results reveal that recycling and water conservation behaviour obtained no or very low scores both for the work and home domains in the 'never' and 'rarely' category. This indicates that both behaviours are well-engrained in each setting, hinting at positive spillover. Surprisingly, composting displays different data since the 'never' data garnered high results. This is also experienced in the following categories: Sustainable transport methods, Purchasing environmentally friendly products and Consuming meatless meals. On the other hand, nearly all other options, the 'daily' category scored the highest.

These results conform with previous studies where respondents are willing to engage in sustainable behaviour that requires less effort, time, and cost since it is difficult to alter and maintain continuous behavioural changes, as McKenzie-Mohr (2000) puts forward. Verfuerth, Jones, Gregory-Smith and Oates (2019) conclude that easy and small changes are considered a positive spillover in their study. The respondents believe that such minor shifts, which are feasible and more controllable, are a step towards a sustainable lifestyle.

Similarly, this study reveals that respondents are unwilling to consume meatless meals, as Truelove and Parks (2012) indicate. Respondents perceive this behaviour as a minimal contribution towards sustainability. Sanchez-Sabate and Joan Sabaté (2019) add that a minority are willing to adopt such a shift since meat consumption is strongly linked with social norms, preferences and cuisines. This is aligned with Rogers' (2003, p.171) ideology mentioned previously in the literature review. Reference to high costs has also surfaced in Diekmann and 
Preisendörfer (1998), when using public transport instead of one’s car, despite being a more sustainable option. In the case of both behaviours, this case study reveals similar results, indicating that these are more determined by habit rather than rationality (Verplanken et al., 1997; Bamberg et al., 2003; Lorenzoni et al., 2007 as cited in Blankenberg and Alhusen, 2019). Therefore, the most arduous task for the government is to find measures such as incentives to persuade people to change their habits gradually.

This constitutes more of 'practicality barriers' rather than 'individuality barriers'. The latter appears to be at a minimum in this study as it seems respondents do not lack laziness or disinterest. However, it transpires that even though individuals are aware of environmental issues, individuals are not willing to adopt drastic lifestyle changes and are not aware of the consequences their decision might imply.

\subsection{Answering Research Question 2}

Research Question 2: To what extent does the intervention utilized affect behaviour?

The intervention demonstrated effectiveness to increase awareness of sustainability. However, as indicated in previous studies such as Kollmuss and Agyeman (2002), awareness in itself does not automatically translate into sustainable behaviour. While the intervention has made participants reflect upon their behaviour, it seems that respondents generally retained their sustainable practices in most instances across both domains.

The results display that the intervention was effective, especially in 'composting' and 'make environmental friendly' purchases. Although the former scored highest in the 'never' category, an increase between pretest and posttest in the 'daily' category was experienced in both domains. The latter experienced this in the 'regularly' category and a consistent score or slight decrease in the 'never' and 'rarely' category. Similarly, 'sustainable transportation' experienced an increase for the 'daily' and regularly' option and a decrease in the 'never' option for both domains.

In addition, a slight increase was obtained in the 'daily' category for 'Reduce, reuse and recycle'. Consistent scores in both domains were obtained in 'Turn off the lights/switch off 
computer' and 'Prevent water wastage' since low scores were obtained for the negative strands of the Likert Scale.

A decrease was experienced in the daily option for both domains in 'The use of energy-efficient bulbs'. However, the 'never' category was only experienced in the work domain and remained stable between the two tests.

Other interesting results between the two tests reveal that the daily use of double-sided printing is stable at home but increases at work, whereas all other strands of the Likert Scale remain stable. The 'regularly' option for 'consuming meatless meals' decreased at work but increased at home. While the 'never' and 'rarely' categories showed consistent results throughout, the 'daily' option garnered a very low score only for the work posttest. This denotes that a slight change might have happened throughout the intervention.

Once the findings have been discussed by answering the two research questions, the following section presents some concluding remarks and pertinent recommendations.

\section{CONCLUDING REMARKS}

This research has reviewed the theoretical foundations of behavioural spillover to apply them for the intervention study. Particular attention was paid to two crucial components of this study: the behavioural traits of public officers in different domains and the effectiveness of the intervention in promoting sustainable behaviour. The pretest and posttest questionnaires yielded some results:

I. Similar behavioural trends are adopted irrespective of domain.

II. Positive spillover occurs for behaviour that involves the least cost, effort and time.

III. Respondents are not willing to make drastic lifestyle changes, and well-engrained practices become part of one's routine, possibly due to the influence of past environmental campaigns or marketing. For example, recycling exhibits robust positive results when compared to composting, which has been recently implemented on a national scale. Therefore, the latter's results still need to be reaped in the future.

IV. An increase in awareness does not automatically translate into promoting sustainable behaviour. 
Based on such findings, the following action points are being recommended, namely:

1. Given that this study focused on measuring public officers' behavioural traits, further studies might explore underlying motives or emotions behind spillover.

2. The findings stemming from this research can be transferable to not only realms of governance but can also aid in the formulation of sustainability programs and campaigns.

3. Greater engagement and alliances between stakeholders, such as the government, policymakers, the general public, and civil society are needed. Being proactive is key to further strengthening policy formulation. Moreover, cross-sector collaboration is critical in solidifying partnerships and base knowledge.

4. Identification of behavioural spillovers within governmental structures is essential, especially in the light of creating a more sustainable public service. Observing, acknowledging and reinforcing sustainable practices is deemed necessary to motivate the workforce to adopt such lifestyles even in their household.

5. The government should employ the use of measures that trigger positive spillover. 'The foot-in-the-door' technique should be an excellent way to help citizens to adopt more strenuous behaviour in the future.

6. The government should create more opportunities and revolutionize the notion of sustainable practices across public administration. Setting high standards is imperative to assist the workforce in focusing on all-inclusive behavioural targets rather than a single target. In addition, more opportunities for effort recognition should be initiated.

All in all, this study has laid the foundations for new pathways of good governance and policy, attested by the infusion of behavioural spillover for sustainability. This calls for a holistic and transformational vision that could improve organizational structures within the government to better society. Further research on these policy suggestions could map out the aforementioned for the well-being of the present and future generations, which is the crux of sustainable development. 


\section{REFERENCES}

Allen, M. (2017), Quasi-Experimental Design In: The SAGE Encyclopedia of Communication Research Methods, Thousand Oaks, CA: SAGE Publications.

Baldwin, L. (2018), Research Concepts for the Practitioner of Educational Leadership, Leiden, The Netherlands: Brill.

Bamberg, S., Ajzen, I. and Schmidt, P. (2003), Choice of travel mode in the theory of planned behavior: The roles of past behavior, habit, and reasoned action. Basic and applied social psychology, 25(3), pp.175-187.

Blankenberg, A.K., and Alhusen, H. (2019), On the determinants of pro-environmental behavior: A literature review and guide for the empirical economist, Cege Discussion Papers, No. 350, University of Göttingen, Center for European, Governance and Economic Development Research (cege), Göttingen.

Byron, K. (2005), A meta-analytic review of work-family conflict and its antecedents. Journal of Vocational Behavior, 67(2), pp. 169-198.

Capstick, S., Lorenzoni, I., Corner, A. and Whitmarsh, L. (2015), Prospects for radical emissions reduction through behavior and lifestyle change. Carbon Management. 5, pp. 429445.

Carver, C. S. (2003), Pleasure as a sign you can attend to something else: Placing positive feelings within a general model of affect, Cognition \& Emotion, Vol 17 No2, pp 241-261.

Cherry, T. L., and Shogren, J. F. (2007), Rationality crossovers, Journal of Economic Psychology, Vol 28 No.2, pp. 261-277.

Crompton, T. (2008), Weathercocks and Signposts: The Environment Movement at a Crossroads, Godalming: World Wildlife Federation.

Crotty, M. (1998), The foundations of social research: Meaning and perspective in the research process, Thousand Oaks, CA: Sage Publications.

Department for Environment Food and Rural Affairs - DEFRA (2008), A Framework for ProEnvironmental Behaviours, Available at:

https://assets.publishing.service.gov.uk/government/uploads/system/uploads/attachment_data/ file/69277/pb13574-behaviours-report-080110.pdf (Accessed 12 September 2021).

Diekmann, A. and Preisendörfer, P. (1998), Environmental consciousness and environmental behavior in low-cost and in high-cost situations, An empirical examination of the low-cost hypothesis, Zeitschrift für Soziologie. Vol 27 No 6, pp 438-453.

Dolan, P., \& Galizzi, M. M. (2015), Like ripples on a pond: Behavioral spillovers and their implications for research and policy, Journal of Economic Psychology, Vol 47, pp. 1-16. 
Eby, L. T., Casper, W. J., Lockwood, A., Bordeaux, C., and Brinley, A. (2005), Work and family research in IO/OB: Content analysis and review of the literature (1980-2002), Journal of Vocational Behavior, 66(1), 124-197.

Edwards, J. and Rothbard, N. (2000), Mechanisms Linking Work and Family: Clarifying the relationship between Work and Family Constructs, The Academy of Management Review, Vol 25 No 1, pp 178-199.

Fadhel, K. (2002), Positivist and Hermeneutic Paradigm, A Critical Evaluation under their \# Structure of Scientific Practice, The Sosland Journal, pp. 21-28.

Futerra, (2006), New rules: New game. Communications tactics for climate change. Available at:http://www.vims.edu/research/units/centerspartners/map/climate/docs_climate/Ne wRules_NewGame.pdf. (Accessed 17 September 2021).

Galizzi, M.M. and Whitmarsh, L. (2019), How to Measure Behavioral Spillovers: A Methodological Review and Checklist, Frontiers in Psychology, Vol 10, Article 342.

Geller, E. S. (2001), Working safe: How to help people actively care for health and safety (2nd ed.). New York: Lewis Publishers.

Gillingham, K., Kotchen, M. J., Rapson, D.S. and Wagner, G., (2013), The rebound effect is overplayed, Nature Vol. 493, pp. 475-476.

Gray, D. B. (1985), Ecological beliefs and behaviors. Westport, CT: Greenwood.

Guadagno, R., Asher, T., Demaine, L. and Cialdini, R. (2001), When Saying Yes Leads to Saying No: Preference for Consistency and the Reverse Foot-in-the-Door Effect, Personality and Social Psychology Bulletin, Vol. 27, pp. 859-867.

Hale, S. (2008), The New Politics of Climate Change: why we are failing and how we will succeed, Green Alliance, Vol 19 No 2, pp 255-275.

Hanson, G.C., Hammer, L.B. and Colton, C.L. (2006), 'Development and validation of a multidimensional scale of perceived work-family positive spillover', Journal of Occupational Health Psychology, Vol 11, pp. 249-265.

Jacobsen, G., Kotchen, M. and Vandenbergh, M. (2012), The Behavioral Response to Voluntary Provision of an Environmental Public Good: Evidence from Residential Electricity Demand, European Economic Review, Vol 56, pp. 946 - 960.

Kollmuss, A. and Agyeman, J. (2002), Mind the Gap: Why do people act environmentally and what are the barriers to pro-environmental behavior?, Environmental Education Research, Vol8 No 3, pp. 239-260.

Levy, Y. and Ellis, T. (2011), A Guide for Novice Researchers on Experimental and QuasiExperimental Studies in Information Systems Research, Interdisciplinary Journal of Information, Vol 6, pp 151-161.

Littleford, C., Ryley, T.J. and Firth, S.K. (2014), Context, control and the spillover of energy 
use behaviours between office and home settings. Journal of Environmental Psychology, 40, pp.157-166.

Loewen, S., \& Plonsky, L. (2015), An A-Z of applied linguistics research methods. New York: Palgrave.

Lorenzoni, I., Nicholson-Cole, S. and Whitmarsh, L. (2007), Barriers perceived to engaging with climate change among the UK public and their policy implications. Global environmental change, 17(3-4), pp.445-459.

Mazar, N., Amir, O. and Ariely, D. (2008), The dishonesty of honest people: A theory of selfconcept maintenance. Journal of marketing research, 45(6), pp.633-644.

McKenzie-Mohr, D. (2000), Promoting sustainable behavior: An introduction to communitybased social marketing, Journal of Social Issues, Vol 56, pp. 543-554.

Nash, N., Whitmarsh, L., Capstick, S., Hargreaves, T., Poortinga, W., Thomas, G, Sautkina, E. and Xenias, D. (2017), Climate-relevant behavioral spillover and the potential contribution of social practice theory: Climate-relevant behavioral spillover, Wiley Interdisciplinary Reviews: Climate Change, Vol 8, pp.1-20.

Nilsson, A., Bergquist, M., and Schultz, W. P. (2016), Spillover effects in environmental behaviors, across time and context: a review and research agenda. Environ. Educ. Res. 3, pp. $1-7$.

NSO, (2014), Malta in figures 2014, Available at: https://nso.gov.mt/en/publicatons/ Publications_by_Unit/Documents/D2_Dissemination_Unit/Malta_in_Figures_2014.pdf (Accessed 4 September);

Oskamp, S. (2000), Psychological contributions to achieving an ecologically sustainable future for humanity, Journal of Social Issues, Vol. 56 No.3, pp. 373-390.

Pickett, G.M., Kangun, N. and Grove, S.J. (1993), Is There a General Conserving Consumer? A Public Policy Concern. Journal of Public Policy \& Marketing, 12, pp. 234 - 243.

Poortinga, W., Whitmarsh, L., and Suffolk, C. (2013), The introduction of a single-use carrier bag charge in Wales: attitude change and behavioural spillover effects. J. Environ. Psychol. 36, pp. 240-247.

Poroli, A. and Huang, L.V. (2018), Spillover Effects of a University Crisis: A Qualitative Investigation Using Situational Theory of Problem Solving, Journalism \& Mass Communication Quarterly, Vol 95 No 4, pp. 1128-1149.

Price, P.C., Jhangiani, R.S., Chiang, I.A., Leighton, D.C. and Cuttler, C. (2017), Research Methods in Psychology, 3rd American edition, Washington: Press Books Publications.

Rashid, N.R.N.A. and Wahid, N.H.A. (2012), Positive spillover of pro-environmental behaviour phenomenon: the influence of organizational and family factors, International Proceedings of Economics Development and Research, Vol 56 No 16, pp. 79-83. 
Rodriguez-Muñoz, A., Sanz Vergel, A. and Demerouti, E. (2013), Engaged at Work and Happy at Home: A Spillover-Crossover Model. Journal of Happiness Studies. 15. 10.1007/s10902013-9421-3.

Rogers, E. (2003), Diffusion of innovations, New York: The Free Press.

Sanchez-Sabate, R. and Sabaté, J. (2019), "Consumer Attitudes Towards Environmental Concerns of Meat Consumption: A Systematic Review" International Journal of Environmental Research and Public Health 16, no. 7: 1220.

Sikora, P., Moore, S., Grunberg, L., and Greenberg, E.S. (2007), Work-Family Conflict: An Exploration of Causal Relationships in a 10-year, 4-wave Panel Study, Workplace Change Project Working Paper WP-018, Available at http://www.colorado.edu/ibs/PEC/workplacechange/papers/WP_018.pdf (Accessed 12 August 2021).

Stratton, S. (2019), Quasi-Experimental Design (Pre-Test and Post-Test Studies) in Prehospital and Disaster Research, Prehospital and Disaster Medicine, Vol 34 No 6, pp. 573-574.

The Malta Independent. (2020), Population in Malta surpasses 500,000 - NSO, Available at: https://www.independent.com.mt/articles/2020-07-10/local-news/Population-in-Maltasurpasses-500-000-NSO-6736225013 (Accessed 23 August 2021).

Thøgersen, J. (1999), The ethical consumer: Moral norms and packaging choice, Journal of Consumer Policy, Vol 22 No. 4, pp. 439-460.

Thøgersen, J. and Crompton, T. (2009), Simple and Painless? The Limitations of Spillover in Environmental Campaigning, J Consum Policy, Vol 32, pp. 141-163.

Thøgersen, J. (2012), Pro-Environmental Spillover Review of Research on the Different Pathways Through Which Performing One Pro-Environmental Behaviour Can Influence the Likelihood of Performing Another, Available at: http://www.behaviourworksaustralia.org/wpcontent/uploads/2015/10/Review-of-spillover-researchJohn-Th\%C3\%B8gersen.pdf (Accessed on 9 September, 2021).

Truelove, H. B., \& Parks, C. (2012), Perceptions of behaviors that cause and mitigate global warming and intentions to perform these behaviors, Journal of Environmental Psychology, Vol 32 No 3, pp. 246-259.

Truelove, H. B., Carrico, A. R., Weber, E. U., Raimi, K. T., \& Vandenbergh, M. P. (2014), Positive and negative spillover of pro-environmental behavior: An integrative review and theoretical framework, Global Environmental Change, Vol 29, pp.127-138.

Tudor, T., Barr, S. and Gilg, A. (2007), A Tale of Two Locational Settings: Is There a Link Between Pro-Environmental Behaviour at Work and at Home?, Local Environment. Vol 12 No 4, pp. 409- 412.

Verfuerth, C., Jones, C. R., Gregory-Smith, D., and Oates, C. (2019), Understanding Contextual Spillover: Using Identity Process Theory as a Lens for Analyzing Behavioral Responses to a Workplace Dietary Choice Intervention. Frontiers in psychology, Vol 10, Article 345. 
Verplanken, B., Aarts, H. and Van Knippenberg, A. (1997), Habit, information acquisition, and the process of making travel mode choices. European journal of social psychology, 27(5), pp.539-560.

Weber, L. (1997), Some Reflections on Barriers to the Efficient Use of Energy, Energy Policy, Vol 25, pp 833-835.

Whitmarsh, L. (2009), Behavioural responses to climate change: Asymmetry of intentions and impacts, Journal of Environmental Psychology, Vol 29 No1, pp 13-23. 